\title{
Minimal or maximal surgery for esophageal cancer?
}

\author{
Katie S. Nason, MD, MPH
}

\footnotetext{
From the Division of Thoracic and Foregut Surgery, Department of Cardiothoracic Surgery, University of Pittsburgh, Pittsburgh, Pa.

Supported by award No. K07CA151613 from the National Cancer Institute. The content is solely the responsibility of the authors and does not necessarily represent the official views of the National Cancer Institute or the National Institutes of Health.

Disclosers: Author has nothing to disclose with regard to commercial support.

Received for publication Sept 28, 2015; accepted for publication Sept 29, 2015; available ahead of print Nov 3 , 2015.

Address for reprints: Katie S. Nason, MD, MPH, Division of Thoracic and Foregut Surgery, Department of Cardiothoracic Surgery, University of Pittsburgh, 5200 Centre Ave, Suite 715, Shadyside Medical Building, Pittsburgh, PA 15232 (E-mail: nasonks@upmc.edu).

J Thorac Cardiovasc Surg 2016;151:633-5

$0022-5223 / \$ 36.00$

Copyright $(\underset{2016}{ } 20 \mathrm{by}$ The American Association for Thoracic Surgery

http://dx.doi.org/10.1016/j.jtcvs.2015.09.118
}

In recently published issues of the Journal of Thoracic and Cardiovascular Surgery, readers have had opportunities to examine a variety of studies focused on improving our understanding of the surgical management of esophageal cancer, including the potential advantages of minimally invasive approaches. ${ }^{1-5}$ These articles provide an opportunity to review changes in the surgical management of esophageal cancer and the key factors influencing quality outcomes.

\section{MINIMAL SURGERY FOR ESOPHAGEAL CANCER: THE ENDOSCOPIC APPROACH}

Of the many advances and changes in the management of esophageal cancer, perhaps the most dramatic shift has been in the approach to high-grade dysplasia and superficially invasive disease. Over the past decade, endoscopic therapies for superficially invasive esophageal carcinomas have overtaken esophagectomy as the primary treatment modality. This has been based primarily on the high rates of disease control demonstrated in the published literature and the nearly nonexistent postprocedure morbidity associated with endoscopic procedures. ${ }^{6,7}$ Whether or not endoscopic resection (mucosal or submucosal) is adequate definitive therapy for superficially invasive cancers is based on the underlying risk of undetected nodal metastasis. ${ }^{8-17}$ The proportions of patients with lymph node metastasis associated with a T1a depth of invasion range widely, from $<3 \%$ to $\sim 9 \%$, whereas the risk associated with T1b depth of invasion is substantially higher $(>25 \%)^{8,11,18-22}$ As such, when considering endoscopic therapy as opposed to esophagectomy, the risk-to-benefit assessment must weigh the likelihood of undertreatment (endoscopic therapy alone in the setting of occult positive lymph nodes) against the potential morbidity and mortality associated with esophagectomy.

Unfortunately, clinical assessment of the depth of tumor invasion is quite poor, with up to $60 \%$ of superficially invasive esophagectomy.

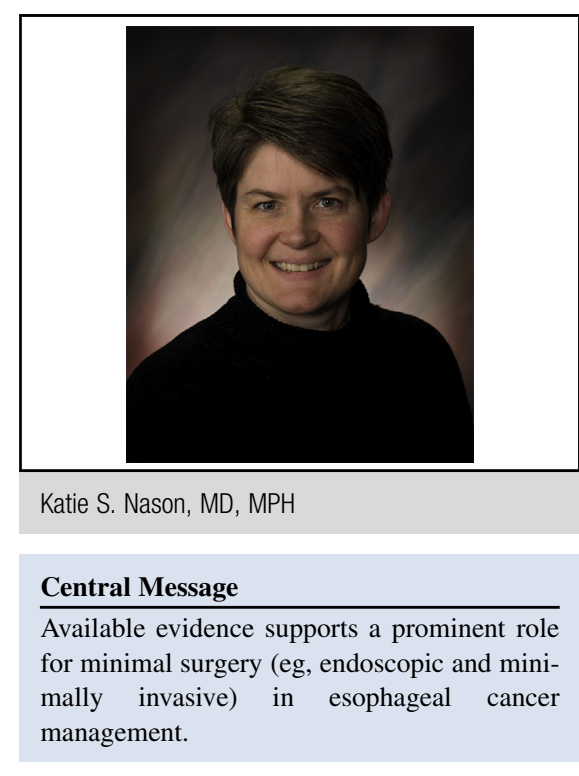

See Article page 806 in the October issue.

cases incorrectly characterized by endoscopic ultrasound. ${ }^{21}$ As a result, to optimize risk stratification in patients with apparently superficially invasive esophageal cancer, endoscopic mucosal resection should be performed, with careful assessment for the presence of high-risk characteristics. ${ }^{23}$ In addition to depth of invasion (mucosal vs submucosal), predictors of lymph node metastasis in superficial esophageal cancer included tumor size $>2 \mathrm{~cm}$, the presence of lymphovascular invasion, and poorly differentiated tumor grade. . $^{9-113}$ When these high-risk characteristics are identified, patients should be counseled regarding the risks of nodal metastasis and recommended for either esophagectomy or definitive chemoradiation, ${ }^{24,25}$ depending upon their fitness for operative intervention as determined by a surgeon with expertise in

\section{MINIMAL VERSUS MAXIMAL SURGERY FOR ESOPHAGECTOMY}

Similar to the drive for minimal surgery to achieve maximal benefit in lung surgery, an increasing number of surgeons are strong proponents for minimally invasive esophagectomy. Potential advantages include reduced blood loss, reduced morbidity during the perioperative phase with faster recovery, and decreased length of hospital stay. ${ }^{26} \mathrm{Re}-$ sults from high-volume esophageal surgery centers have been excellent, with low mortality rates and acceptable 
morbidity. ${ }^{27}$ The oncologic adequacy of a minimally invasive approach was also established, with many singlecenter studies showing rates of complete resection, lymph node retrieval, and survival similar to the rates achieved with Ivor Lewis and McKeown esophagectomy. ${ }^{28-30}$ Detractors, however, cite a lack of prospective data supporting minimally invasive esophagectomy as superior to open esophagectomy and a wide variation in the definition of a minimally invasive esophagectomy ${ }^{31}$; indeed, until a few years ago there were few prospective studies and no randomized trials showing even equivalent outcomes, let alone superior ones. Prospective and randomized trial results are now available that clearly establish the safety of minimally invasive esophagectomy as primary treatment as well as following induction therapy. ${ }^{32,33}$ The first randomized controlled trial of minimally invasive versus open esophagectomy was published during 2012. ${ }^{34}$ That multicenter trial from the Netherlands was powered to examine differences in pulmonary infection within the first 2 weeks after resection and found that the relative risk was $70 \%$ less after minimally invasive esophagectomy compared with an open approach. Length of hospital stay and complete resection also favored minimally invasive esophagectomy, as did pain scales and short-term quality of life (as measured by the Short-Form 36 and the European Organization for Research and Treatment of Cancer Quality of Life Questionnaire Cancer 30 and Esophagus 18 measures). There were no differences in pathologic stage or total lymph nodes retrieved. Mortality at 30 days and during hospital stay were not significantly different. ${ }^{34}$ Although the trial was not powered to demonstrate a difference in quality of life, the early improvements in quality-of-life measures were sustained. At 1-year follow-up, measures of physical health, global health, and pain were all significantly better for the patients who were treated with a minimally invasive approach compared with an open esophagectomy. ${ }^{35}$ Wang and colleagues, ${ }^{2}$ using a propensity-matched comparison of open and minimally invasive esophagectomy, also found that scores were higher for physical function and global quality of life, with less fatigue, pain, and dyspnea in the minimally invasive cohort, especially during the first year of survival after esophagectomy.

\section{PREDICTING MORBIDITY AND MORTALITY AFTER MINIMAL OR MAXIMAL ESOPHAGECTOMY}

Despite the advantages offered by a minimally invasive approach to esophagectomy, there is still a significant risk of major complications and the potential for fatal outcomes. As such, appropriate patient selection continues to be vitally important. A number of authors from centers of excellence for esophageal surgery have examined a variety of predictors to aid surgeons in risk stratification for postoperative morbidity and mortality. The majority of these efforts have focused on developing preoperative risk stratification tools, including the Charlson comorbidity index, frailty indices, ${ }^{36}$ nutritional risk assessment, ${ }^{37}$ and other preoperative clinical parameters. ${ }^{38}$ Intraoperative risk stratification tools may also prove useful for patient-specific treatment protocols. For example, use of the intensive care unit may not be necessary for all patients, but may improve outcomes for patients with high preoperative or intraoperative risk score for postoperative morbidity and mortality. Using intraoperative heart rate, mean arterial blood pressure, and blood loss, Janowak and colleagues ${ }^{1}$ found that a modified esophagectomy Surgical Apgar Score of 6 or less was strongly and independently associated with 30-day major morbidity and suggested that this score could be used to aid clinicians in postoperative decision making (eg, riskstratified triage of patients and modification of postoperative care) to optimize outcomes and resource use. Increased use of these types of preoperative and intraoperative riskstratification tools may aid clinicians in reducing postoperative complications and identifying patients who might be at increased risk for difficult-to-manage complications requiring a more intensive initial hospitalization. Indeed, hospital readmissions after esophagectomy, an increasingly important and influential quality measure, appear to be directly related to complications identified at the initial hospitalization, most commonly pulmonary issues, anastomotic complications, gastrointestinal complaints, and venous thromboembolism. ${ }^{3}$

\section{MINIMAL OR MAXIMAL SURGERY FOR ESOPHAGEAL CANCER?}

Although the ultimate answer to this question depends on the characteristics of the patient, the tumor, and the treating physicians, the available evidence increasingly favors a prominent role for minimally invasive approaches in the management of esophageal cancer. Endoscopic therapies and minimally invasive approaches offer at least equivalent oncologic outcomes, with reduced complications and improved quality of life compared with maximal surgery. When used in combination with established preoperative and intraoperative risk-stratification tools, treatment protocols, and postoperative pathways, minimal surgery for esophageal cancer can provide maximal patient benefit.

\footnotetext{
References

1. Wang H, Shen Y, Feng M, Zhang Y, Jiang W, Xu S, et al. Outcomes, quality of life, and survival after esophagectomy for squamous cell carcinoma: a propensity score-matched comparison of operative approaches. J Thorac Cardiovasc Surg. 2015;149:1006-14.

2. Shah SP, Xu T, Hooker CM, Hulbert A, Battafarano RJ, Brock MV, et al. Why are patients being readmitted after surgery for esophageal cancer? J Thorac Cardiovasc Surg. 2015;149:1384-9.

3. Gillaspie EA, Blackmon SH. Now that reimbursement for readmission to the hospital is threatened, we are finally focused on readmissions after esophagectomy. J Thorac Cardiovasc Surg. 2015;149:1392-3.
} 
4. Janowak CF, Blasberg JD, Taylor L, Maloney JD, Macke RA. The Surgical Apgar Score in esophagectomy. J Thorac Cardiovasc Surg. 2015;150:806-12.

5. Zahoor H, Luketich JD, Levy RM, Awais O, Winger DG, Gibson MK, et al. A propensity-matched analysis comparing survival after primary minimally invasive esophagectomy followed by adjuvant therapy to neoadjuvant therapy for esophagogastric adenocarcinoma. J Thorac Cardiovasc Surg. 2015;149:538-47.

6. Zehetner J, DeMeester SR, Hagen JA, Ayazi S, Augustin F, Lipham JC, et al. Endoscopic resection and ablation versus esophagectomy for high-grade dysplasia and intramucosal adenocarcinoma. J Thorac Cardiovasc Surg. 2011; 141:39-47.

7. Pech O, May A, Manner H, Behrens A, Pohl J, Weferling M, et al. Long-term efficacy and safety of endoscopic resection for patients with mucosal adenocarcinoma of the esophagus. Gastroenterology. 2014;146:652-60.e1.

8. Dubecz A, Kern M, Solymosi N, Schweigert M, Stein HJ. Predictors of lymph node metastasis in surgically resected T1 esophageal cancer. Ann Thorac Surg. 2015;99:1879-85.

9. Landau MS, Hastings SM, Foxwell TJ, Luketich JD, Nason KS, Davison JM. Tumor budding is associated with an increased risk of lymph node metastasis and poor prognosis in superficial esophageal adenocarcinoma. Mod Pathol. 2014;27:1578-89.

10. Li B, Chen H, Xiang J, Zhang Y, Kong Y, Garfield DH, et al. Prevalence of lymph node metastases in superficial esophageal squamous cell carcinoma. J Thorac Cardiovasc Surg. 2013;146:1198-203.

11. Lee L, Ronellenfitsch U, Hofstetter WL, Darling G, Gaiser T, Lippert C, et al. Predicting lymph node metastases in early esophageal adenocarcinoma using a simple scoring system. J Am Coll Surg. 2013;217:191-9.

12. Xue L, Ren L, Zou S, Shan L, Liu X, Xie Y, et al. Parameters predicting lymph node metastasis in patients with superficial esophageal squamous cell carcinoma. Mod Pathol. 2012;25:1364-77.

13. Sgourakis G, Gockel I, Lyros O, Lanitis S, Dedemadi G, Polotzek U, et al. The use of neural networks in identifying risk factors for lymph node metastasis and recommending management of T1b esophageal cancer. Am Surgeon. 2012; 78:195-206.

14. Gockel I, Domeyer M, Sgourakis GG, Schimanski CC, Moehler M, Kirkpatrick CJ, et al. Prediction model of lymph node metastasis in superficial esophageal adenocarcinoma and squamous cell cancer including D2-40 immunostaining. J Surg Oncol. 2009;100:191-8.

15. Ancona E, Rampado S, Cassaro M, Battaglia G, Ruol A, Castoro C, et al. Prediction of lymph node status in superficial esophageal carcinoma. Ann Surg Oncol. 2008;15:3278-88.

16. Shimada H, Nabeya Y, Matsubara H, Okazumi S, Shiratori T, Shimizu T, et al. Prediction of lymph node status in patients with superficial esophageal carcinoma: analysis of 160 surgically resected cancers. Am J Surg. 2006;191:250-4.

17. Liu L, Hofstetter WL, Rashid A, Swisher SG, Correa AM, Ajani JA, et al. Significance of the depth of tumor invasion and lymph node metastasis in superficially invasive (T1) esophageal adenocarcinoma. Am J Surg Pathol. 2005;29:1079-85.

18. Pennathur A, Farkas A, Krasinskas AM, Ferson PF, Gooding WE, Gibson MK, et al. Esophagectomy for T1 esophageal cancer: outcomes in 100 patients and implications for endoscopic therapy. Ann Thorac Surg. 2009;87:1048-54.

19. Plum PS, Warnecke-Eberz U, Dhaouadi O, Alakus H, Drebber U, Metzger R, et al. Molecular markers predicting lymph node metastasis in early esophageal cancer. Histol Histopathol. 2015;30:1193-202.

20. Gertler R, Stein HJ, Schuster T, Rondak IC, Hofler H, Feith M. Prevalence and topography of lymph node metastases in early esophageal and gastric cancer. Ann Surg. 2014;259:96-101.

21. Bergeron EJ, Lin J, Chang AC, Orringer MB, Reddy RM. Endoscopic ultrasound is inadequate to determine which T1/T2 esophageal tumors are candidates for endoluminal therapies. J Thorac Cardiovasc Surg. 2014;147:765-71.
22. Dunbar KB, Spechler SJ. The risk of lymph-node metastases in patients with high-grade dysplasia or intramucosal carcinoma in Barrett's esophagus: a systematic review. Am J Gastroenterol. 2012;107:850-62.

23. Pech O, Gunter E, Dusemund F, Origer J, Lorenz D, Ell C. Accuracy of endoscopic ultrasound in preoperative staging of esophageal cancer: results from a referral center for early esophageal cancer. Endoscopy. 2010;42:456-61.

24. Kawaguchi G, Sasamoto R, Abe E, Ohta A, Sato H, Tanaka K, et al. The effectiveness of endoscopic submucosal dissection followed by chemoradiotherapy for superficial esophageal cancer. Radiat Oncol. 2015;10:31.

25. Mochizuki Y, Saito Y, Tsujikawa T, Fujiyama Y, Andoh A. Combination of endoscopic submucosal dissection and chemoradiation therapy for superficial esophageal squamous cell carcinoma with submucosal invasion. Exp The Med. 2011;2:1065-8

26. Nagpal K, Ahmed K, Vats A, Yakoub D, James D, Ashrafian H, et al. Is minimally invasive surgery beneficial in the management of esophageal cancer? A meta-analysis. Surg Endosc. 2010;24:1621-9.

27. Luketich JD, Pennathur A, Awais O, Levy RM, Keeley S, Shende M, et al Outcomes after minimally invasive esophagectomy: review of over 1000 patients. Ann Surgery. 2012;256:95-103.

28. Dantoc M, Cox MR, Eslick GD. Evidence to support the use of minimally invasive esophagectomy for esophageal cancer: a meta-analysis. Arch Surg. 2012;147:768-76.

29. Smithers BM, Gotley DC, Martin I, Thomas JM. Comparison of the outcomes between open and minimally invasive esophagectomy. Ann Surg. 2007;245 232-40.

30. Sgourakis G, Gockel I, Radtke A, Musholt TJ, Timm S, Rink A, et al. Minimally invasive versus open esophagectomy: meta-analysis of outcomes. Dig Dis Sci. 2010;55:3031-40.

31. Hanna GB, Arya S, Markar SR. Variation in the standard of minimally invasive esophagectomy for cancer-systematic review. Sem Thorac Cardiovasc Surg. 2012;24:176-87.

32. Luketich JD, Pennathur A, Franchetti Y, Catalano PJ, Swanson S, Sugarbaker DJ, et al. Minimally invasive esophagectomy: results of a prospective phase II multicenter trial-the eastern cooperative oncology group (E2202) study. Ann Surg. 2015;261:702-7.

33. Spector R, Zheng Y, Yeap BY, Wee JO, Lebenthal A, Swanson SJ, et al. Threehole minimally invasive esophagectomy — a safe procedure following neoadjuvant chemotherapy and radiation. Sem Thorac Cardiovasc Surgery. 2015;27: 205-15.

34. Biere SS, van Berge Henegouwen MI, Maas KW, Bonavina L, Rosman C Garcia JR, et al. Minimally invasive versus open oesophagectomy for patients with oesophageal cancer: a multicentre, open-label, randomised controlled trial Lancet. 2012;379:1887-92.

35. Maas KW, Cuesta MA, van Berge Henegouwen MI, Roig J, Bonavina L, Rosman C, et al. Quality of life and late complications after minimally invasive compared to open esophagectomy: results of a randomized trial. World J Surg. 2015;39:1986-93.

36. Hodari A, Hammoud ZT, Borgi JF, Tsiouris A, Rubinfeld IS. Assessment of morbidity and mortality after esophagectomy using a modified frailty index. Ann Thorac Surg. 2013;96:1240-5.

37. Yamana I, Takeno S, Shibata R, Shiwaku H, Maki K, Hashimoto T, et al. Is the Geriatric Nutritional Risk Index a significant predictor of postoperative complications in patients with esophageal cancer undergoing esophagectomy? Eur Surg Res. 2015;55:35-42.

38. Wright CD, Kucharczuk JC, O'Brien SM, Grab JD, Allen MS, Society of Thoracic Surgeons General Thoracic Surgery Database. Predictors of major morbidity and mortality after esophagectomy for esophageal cancer: a Society of Thoracic Surgeons General Thoracic Surgery Database risk adjustment model. J Thorac Cardiovasc Surg. 2009;137:587-95. 